\title{
Platelet Antibodies, Activated Platelets and Serum Leptin in Childhood Immune Thrombocytopenic Purpura
}

\author{
Hosny Badrawy ${ }^{\text {a }}$ Khalid I. Elsayh ${ }^{\mathrm{b}}$ Asmaa M. Zahran ${ }^{\mathrm{a}}$ \\ Mohamad Hamdy EL-Ghazali ${ }^{b}$ \\ a Oncological Clinical Pathology Department, South Egypt Cancer Institute and b Paediatric Department, \\ Faculty of Medicine, Assiut University, Assiut, Egypt
}

\section{Key Words}

Leptin · Platelet antibodies - Thrombocytopenic purpura
ITP pathogenesis. Additionally, activated platelets and serum leptin could have prognostic significance in paediatric acute ITP.

Copyright $\odot 2013$ S. Karger AG, Basel

\begin{abstract}
Background/Aim: The aim of this study was to evaluate the levels of platelet-associated antibodies (PAlgG and PAlgM), activated platelets and serum leptin in children with acute immune thrombocytopenic purpura (ITP). Methods: The study included 40 patients with ITP and 40 healthy age- and sex-matched controls. PAlgG, PAlgM and activated platelet levels were estimated by flow cytometry, and serum leptin levels were estimated by ELISA. Results: Activated platelets and serum leptin were significantly higher in the ITP patients than in the controls. The percentage and mean florescence intensity of PAlgG and PAlgM staining were significantly higher in the patients than in the controls. Serum leptin and activated platelet levels in patients with thrombocytopenia of brief duration were significantly lower than those in patients with thrombocytopenia of prolonged duration. The levels of activated platelets, serum leptin and PAlgG were positively correlated, and the levels of serum leptin, activated platelets and platelet counts were negatively correlated. Conclusion: The increased levels of activated platelets, serum leptin and platelet-associated antibodies in children with acute ITP suggest that these factors could play a role in
\end{abstract}

\section{KARGER}

E-Mail karger@karger.com

www.karger.com/aha
(C) 2013 S. Karger AG, Basel

0001-5792/13/1304-0312\$38.00/0

\section{Introduction}

Immune thrombocytopenic purpura (ITP) is an autoimmune disorder that is considered one of the most common haematologic disorders in children. Approximately $4-5$ cases occur per 100,000 children per year [1]. ITP is characterised by isolated thrombocytopenia with platelet counts $<100 \times 10^{9} / 1$ in the absence of any obvious cause [2]. Chronic ITP, which is more common in adults, persists for $\geq 1$ year [1]. For unknown reasons, platelet surface proteins become antigenic and stimulate the immune system to produce auto-antibodies and to induce cytotoxic T lymphocytes. This phenomenon results in the immune-mediated destruction of the platelets and decreases platelet production [3-5]. Once coated with antibodies, circulating platelets undergo sequestration via interactions with Fc receptors on macrophages in the reticulo-endothelial system [6]. These antibodies accelerate early platelet destruction by the mononuclear phagocyte system; this phenomenon occurs primarily in the spleen, 
as well as in the liver and bone marrow. Patients with chronic ITP often have anti-platelet antibodies with specificities for multiple glycoproteins (GP), such as antiGPIIb/IIIa, anti-GPIb/IX and anti-GPIa/IIa [3].

Leptin is an adipocyte-derived cytokine-like hormone that was initially described as a modulator of energy expenditure and of food intake via binding to its long-form receptor, which is expressed in the hypothalamus [7]. Further studies have indicated that leptin plays a significant role in the pathogenesis of several auto-immune diseases [8]. Estimations of platelet function in patients with thrombocytopenia are difficult due to the low platelet counts. Flow-cytometric assays can be used to assess platelet function [9]. Panzer et al. [10] used flow cytometry to show that patients with untreated ITP have platelets that are more activated by flow cytometry than platelets from controls, as determined by the increased expression levels of P-selectin and activated GPIIb/IIIa. Activated platelets in patients with ITP might be associated with a tendency to develop thrombosis, so many patients with ITP do not present with significant bleeding, even in the presence of severe thrombocytopenia $[11,12]$. The aim of this study was to evaluate the levels of platelet-associated antibodies, activated platelets and serum leptin in children with acute ITP.

\section{Patients and Methods}

This study was a prospective case-controlled study that included 40 paediatric patients with acute ITP. The patients were recruited from the Paediatric Clinical Haematology Unit of the Children's Hospital, Assiut University. Additionally, 40 healthy children were included as age- and sex-matched controls. The study was approved by the Institutional Review Board of the Faculty of Medicine, Assiut University, and informed consent was obtained from the guardians of both the patients and the controls. At diagnosis, all patients and controls were subjected to thorough historical and physical examinations in addition to the following investigations: full blood analysis (Celltac E automated haematology analyser; Nihon Kohden, Tokyo, Japan), flow-cytometric analysis of platelet-associated immunoglobulins (PAIgs) IgG and IgM and activated platelets (CD62p expression) and ELISA estimation of serumleptin levels (DRG Instruments GmbH, Marburg, Germany). The patients were managed according to their grades of ITP severity [13]. The patients were further classified into two groups according to the disease course as either patients with disease of short duration, which was defined as recovery in $<3$ months, or as patients with disease of long duration, which was defined as no recovery within 3 months, according to the clinical score developed by Edslev et al. [14].

Inclusion Criteria

(1) Children from 3 months to 16 years of age who presented with newly diagnosed acute ITP.

(2) Platelet count $<20 \times 10^{9} / 1$.
(3) Bleeding tendency less than grade 4 [13]

(4) No prior immunomodulating (e.g. intravenous immunoglobulin or corticosteroids) treatments before diagnosis.

\section{Exclusion Criteria}

(1) Clinical and laboratory features that were not compatible with a diagnosis of acute ITP, such as the presence of organomegaly, other cytopenias besides thrombocytopenia, other auto-immune phenomena or features suggestive of infectious disease, e.g. hepatitis and the Epstein-Barr virus.

(2) Patients with chronic ITP (thrombocytopenia that persisted $\geq 1$ year after the onset of illness) [1].

(3) Immunomodulating treatments within 4 weeks before diagnosis. [13].

(4) Severe or life-threatening bleeding at presentation (grade 4)

Flow-Cytometric Detection of PAIgs and Activated Platelets

To detect PAIgs and activated platelets, $50 \mu \mathrm{l}$ of each blood sample were mixed with $5 \mu \mathrm{l}$ of monoclonal antibodies as follows: fluorescein isothiocyanate (FITC)-conjugated IgG and phycoerythrin (PE)-conjugated CD41 were added to cells in the first tube, FITC-conjugated IgM and PE-conjugated CD61 were added to the second tube and FITC-conjugated CD61 and PE-conjugated CD62 $p$ were added to the third tube. All monoclonal antibodies were purchased from Becton Dickinson Biosciences (San Jose, Calif., USA) except for IgM (Beckman Coulter, Roissy, France). The tubes were incubated for $15 \mathrm{~min}$ at room temperature in the dark. A red blood cell lysis step was performed. After a single wash, the cells were resuspended in phosphate-buffered saline and analysed on a FACSCalibur flow cytometer with CellQuest software (Becton Dickinson Biosciences). Anti-human IgG was used as an isotypematched negative control for each sample. The platelets (R1) were identified according to their forward and side scatter characteristics. The percentages of CD41 and CD61 (platelet GP)-positive cells were determined in the platelet gate. Next, the expression levels of IgM, IgG or CD62p in the CD41+ or CD61+ population were determined. The levels of IgM, IgG and CD62p were determined as percentages of antibody-positive cells and as the geometric mean fluorescence intensity (MFI). Positivity was defined as fluorescence higher than that of the isotype control (fig. 1).

\section{Statistical Analysis}

Data analysis was performed with the Statistical Package for Social Sciences (SPSS version 16). The data were expressed as means \pm SEM. Due to the small sample size and a propensity for outliers in some of the variables, statistical differences between the groups were examined using the Mann-Whitney test. A Spearman correlation test was used to assess the correlations among the different parameters studied. A value of $\mathrm{p} \leq 0.05$ denoted a statistically significant difference.

\section{Results}

The baseline characteristics of the patients and controls are presented in table 1 . There were no significant differences between the ITP patients and the controls regarding 


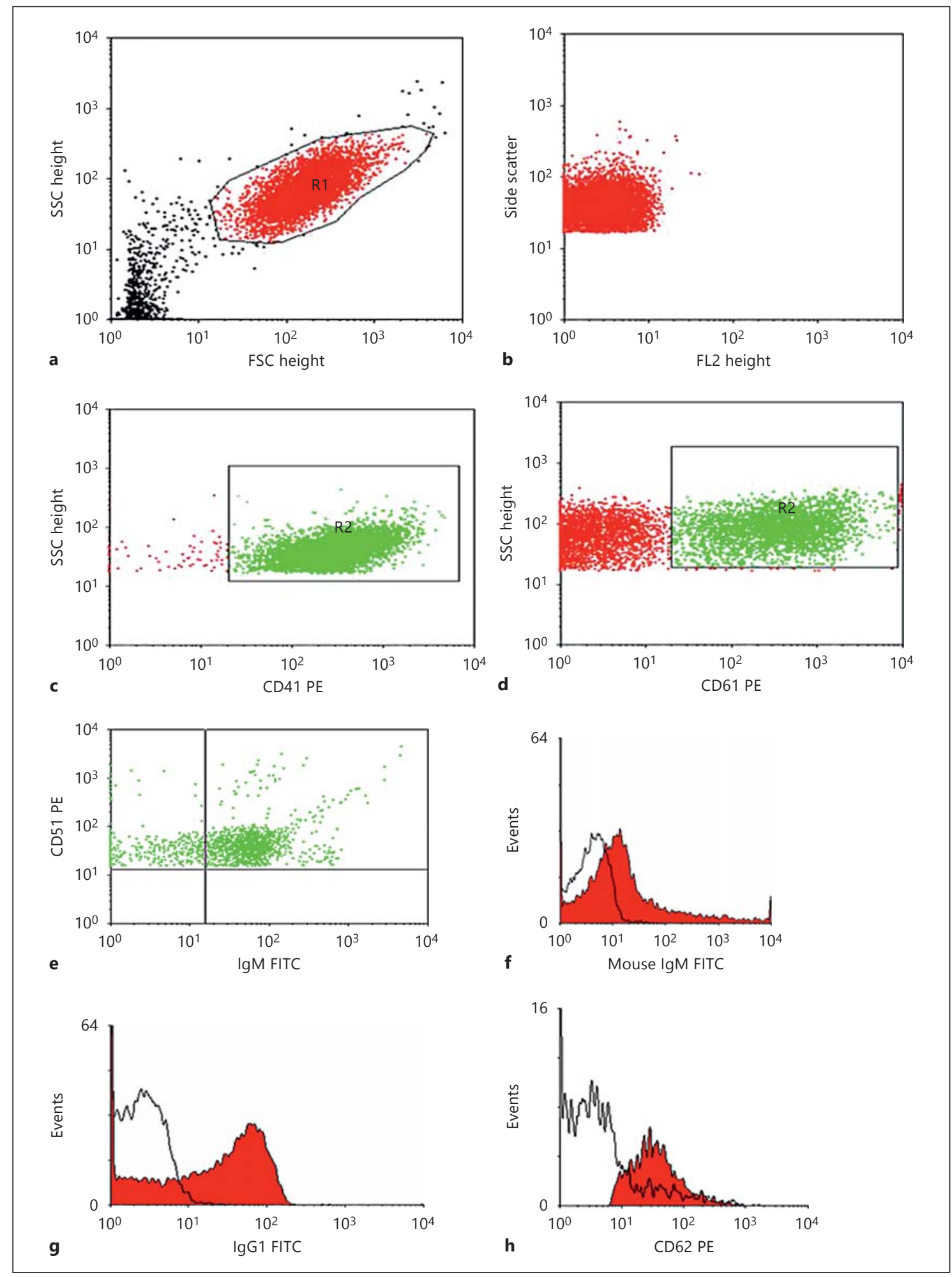

Fig. 1. Flow-cytometric detection of PAIg and platelet activation. Forward and side scatter histogram was used to define the platelet population (R1; a). The percentages of CD41 and CD61 were determined in the platelet population compared to the isotype control (b-d). Then, the expression of IgM, IgG or CD62p in the
CD41+ or CD61+ population (R2) was detected. The level of IgM, IgG or CD62p was detected as percentage of antibody-positive cells and as geometric MFI (e-h). The positivity was defined as fluorescence (red histogram) higher than that of the isotype control (open histogram). 
Table 1. Baseline characteristics of ITP patients and controls

\begin{tabular}{lccr}
\hline Characteristics & $\begin{array}{c}\text { Patients } \\
(\mathrm{n}=40)\end{array}$ & $\begin{array}{l}\text { Controls } \\
(\mathrm{n}=40)\end{array}$ & p value \\
\hline Age, years & $5.65 \pm 0.71$ & $6.07 \pm 0.71$ & \\
Sex, males/females & $22 / 18$ & $24 / 16$ & \\
Petechia & $40 / 40$ & $0 / 40$ & \\
Purpura & $40 / 40$ & $0 / 40$ & \\
Ecchymosis & $40 / 40$ & $0 / 40$ & \\
Epistaxis, mild & $5 / 40$ & $0 / 40$ & \\
Splenomegaly & $0 / 40$ & $0 / 40$ & \\
Hepatomegaly & $0 / 40$ & $0 / 40$ & \\
Medication & supportive, & - & \\
& steroid, Ig & & \\
Platelets, $\times 10^{9} / 1$ & $11.43 \pm 1.09$ & $261.45 \pm 15.1$ & $<0.001$ \\
WBCs, $\times 10^{9} / 1$ & $6.00 \pm 0.34$ & $6.52 \pm 0.39$ & 0.322 \\
Haemoglobin, g/dl & $11.14 \pm 0.27$ & $11.51 \pm 0.26$ & 0.693 \\
MPV, fl & $9.48 \pm 0.33$ & $7.30 \pm 0.16$ & $<0.001$ \\
\hline
\end{tabular}

Mann-Whitney test. Means \pm SEM. MPV $=$ Mean platelet volume; WBCs = white blood cells.

Table 2. Serum leptin, platelet antigen, PAIgs and activated platelets in ITP patients and controls

\begin{tabular}{llrr}
\hline $\begin{array}{l}\text { Parameter } \\
\text { measured }\end{array}$ & $\begin{array}{l}\text { Patients } \\
(\mathrm{n}=40)\end{array}$ & $\begin{array}{l}\text { Controls } \\
(\mathrm{n}=40)\end{array}$ & p value \\
\hline Serum leptin, ng/ml & $13.93 \pm 1.66$ & $6.81 \pm 0.75$ & $<0.001$ \\
CD41+, \% & $65.55 \pm 3.28$ & $87.99 \pm 0.97$ & 0.002 \\
CD61+, \% & $58.13 \pm 2.71$ & $65.03 \pm 3.23$ & 0.134 \\
CD62p+, \% & $26.44 \pm 3.92$ & $10.51 \pm 1.37$ & $<0.001$ \\
MFI of CD62 & $29.62 \pm 4.23$ & $3.38 \pm 0.54$ & $<0.001$ \\
IgM, \% & $32.53 \pm 4.15$ & $7.17 \pm 0.71$ & 0.002 \\
MFI of IgM & $34.84 \pm 4.57$ & $2.30 \pm 0.23$ & $<0.001$ \\
IgG, \% & $41.82 \pm 4.05$ & $9.52 \pm 0.98$ & 0.002 \\
MFI of IgG & $46.87 \pm 5.46$ & $2.72 \pm 0.31$ & $<0.001$ \\
\hline
\end{tabular}

Mann-Whitney test. Means \pm SEM.
Table 3. Clinical and laboratory data in patients with brief duration and patients with prolonged duration of thrombocytopenia

\begin{tabular}{llll}
\hline & $\begin{array}{l}\text { Patients } \\
\text { with brief } \\
\text { ITP duration } \\
(\mathrm{n}=29)\end{array}$ & $\begin{array}{l}\text { Patients with } \\
\text { prolonged } \\
\text { ITP duration } \\
(\mathrm{n}=11)\end{array}$ & $\mathrm{p}$ value \\
\hline Age, years & $4.10 \pm 0.33$ & $10.69 \pm 0.45$ & 0.000 \\
Platelet count, $\times 10^{9} / 1$ & $9.11 \pm 0.97$ & $13.34 \pm 0.67$ & 0.002 \\
IgG, \% & $37.13 \pm 3.07$ & $44.50 \pm 4.47$ & 0.165 \\
IgM, \% & $39.52 \pm 3.86$ & $26.81 \pm 3.88$ & 0.180 \\
CD41, \% & $62.82 \pm 2.96$ & $52.40 \pm 1.96$ & 0.016 \\
CD61, \% & $65.39 \pm 3.74$ & $65.69 \pm 2.9$ & 0.882 \\
CD62p, \% & $25.23 \pm 3.42$ & $42.20 \pm 3.96$ & 0.003 \\
Serum leptin, ng/ml & $10.08 \pm 1.08$ & $18.33 \pm 1.77$ & 0.000 \\
\hline
\end{tabular}

Mann-Whitney test. Means \pm SEM.

cell level, which is represented by MFI, were significantly higher in the patients than controls. Simultaneously, MFI of PAIgG and PAIgM was significantly higher in the patients than in the controls (table 2).

Positive correlations were observed between the serum leptin and PAIgG levels $(r=0.552 ; \mathrm{p}=0.001$; fig. 2$)$ and between the serum leptin level and the percentage of activated platelets $(\mathrm{r}=0.796 ; \mathrm{p}=0.000$; fig. 3 ). However, negative correlations were observed between the platelet count and the serum leptin level $(r=-0.876 ; p=0.000$; fig. 4) and between the platelet count and the activated platelets $(\mathrm{r}=-0.504 ; \mathrm{p}=0.001$; fig. 5). The serum leptin levels and the percentage of activated platelets were significantly lower in patients with thrombocytopenia of brief duration than in patients with thrombocytopenia of prolonged duration. Finally, the PAIgG and PAIgM levels did not significantly differ between patients with thrombocytopenia of brief duration and those with thrombocytopenia of prolonged duration (table 3 ).

\section{Discussion}

In our study patients, the elevated PAIgG and PAIgM levels suggest that the flow-cytometric detection of platelet-associated antibodies can be used to diagnose acute ITP. Our results agree with those of Yildirmak et al. [15], who found that PAIgG levels were increased in acute and chronic ITP patients compared with those in the controls and that the PAIgM levels were significantly higher in acute ITP patients than in the controls. Shao et al. [16] 


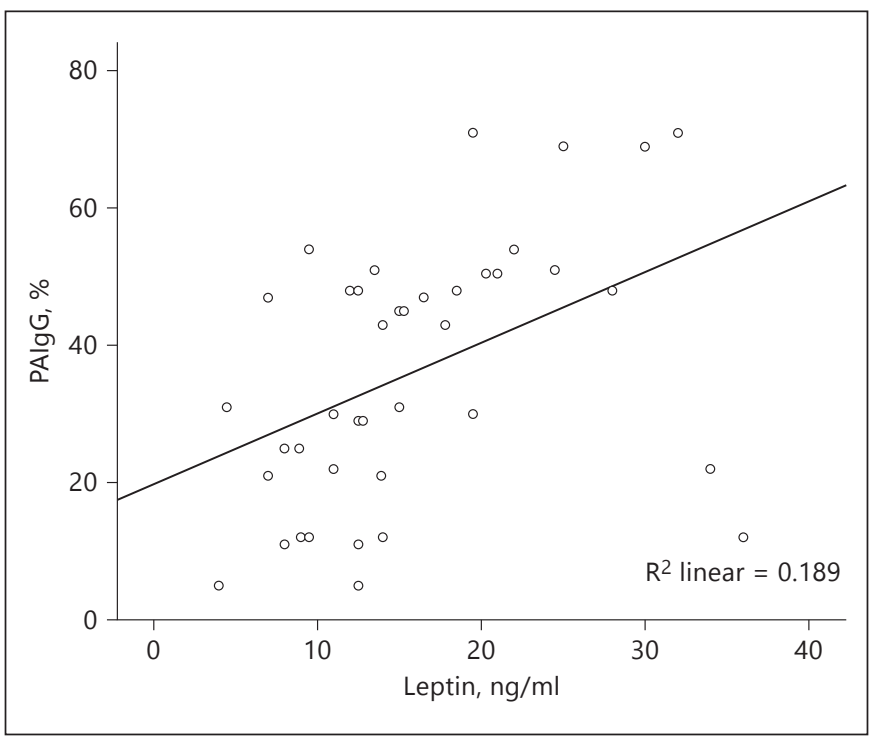

Fig. 2. There is a positive correlation between leptin and PAIgG.

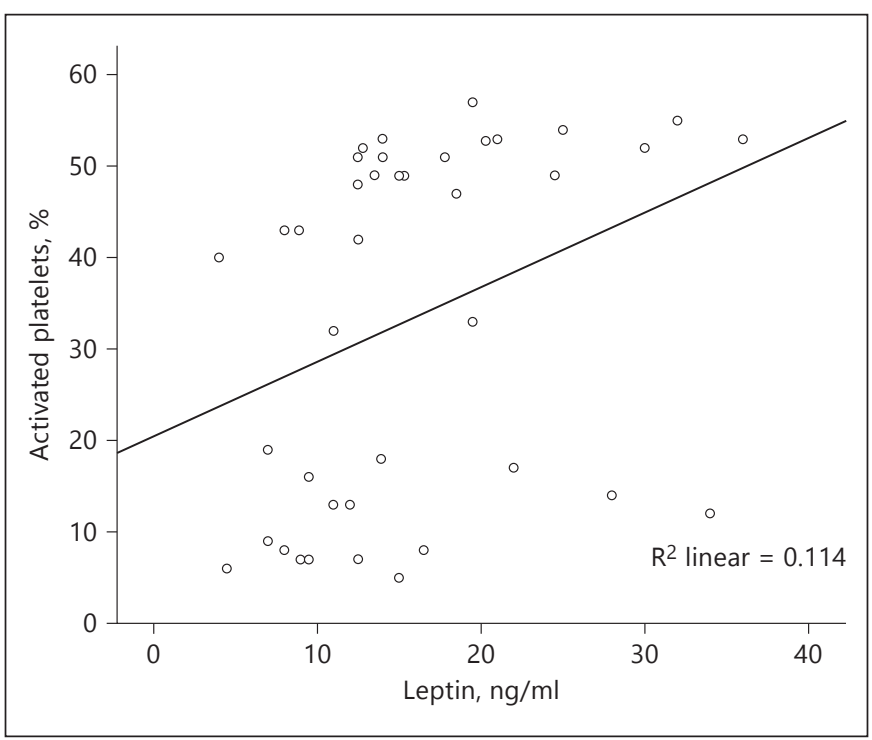

Fig. 3. There is positive a correlation between leptin and activated platelets.

also reported that PAIg levels, including PAIgG, PAIgM and PAIgA, were higher in ITP patients than in the controls and that the PAIg levels decreased after treatment. Furthermore, Romero-Guzmán et al. [17] and Corash and Rheinschmidt [18] reported that PAIgG and PAIgM measurements are highly sensitive for the diagnosis of patients with classical immune-mediated thrombocytope-

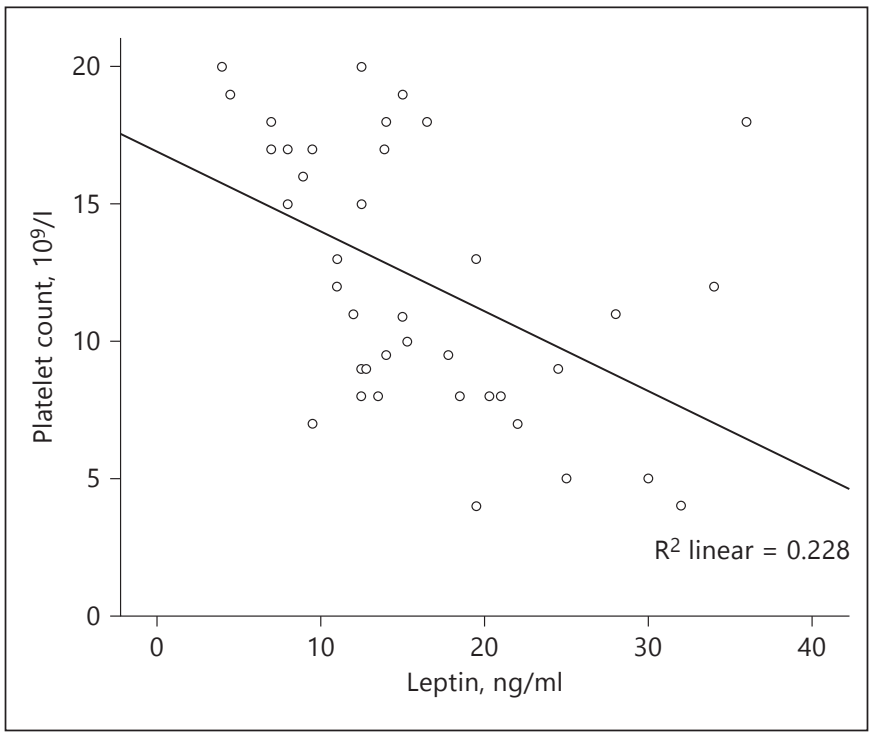

Fig. 4. There is a negative correlation between leptin and platelet count.

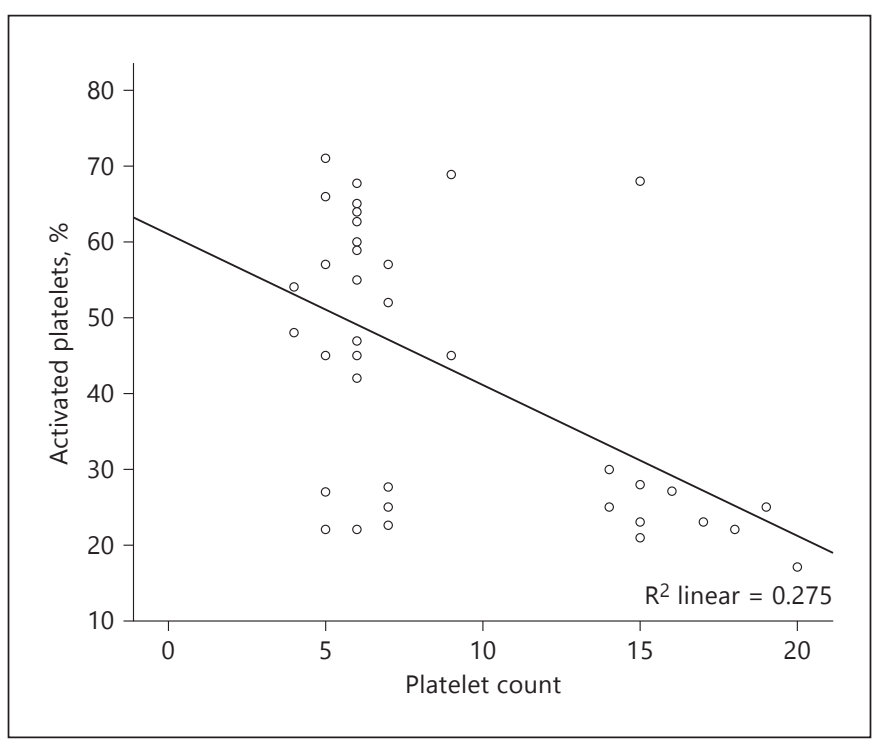

Fig. 5. There is negative correlation between the platelet count and activated platelets.

nia. Similarly, Rosenfeld et al. [19] evaluated PAIgG, PAIgM and PAIgA levels in 50 patients with immune thrombocytopenia and in 44 patients with non-immune thrombocytopenia and found a sensitivity of $92 \%$.

CD41 expression in our patients might be due to the binding of the platelet membrane GP by the PAIgs that were detected in our patients. CD61 expression did not 
differ between the patients and the controls. This result might be because the ITP-associated auto-antibodies could have a higher affinity for the CD41 antibody binding sites than for the CD61 sites. ITP patients often have antiplatelet antibodies that target multiple platelet GPs [3]. Our results are in agreement with those of Kahng et al. [20], who reported that ITP patients had reduced numbers of CD41 antibody binding sites compared with the normal controls, yet the numbers of CD61 sites did not significantly differ between the patients and the controls. Shao et al. [16] reported that the blood levels of platelet membrane GPs were lower in ITP patients than in the controls.

The significantly elevated serum leptin levels, as well as the positive and negative correlations of the serum leptin level with the PAIgG levels and with the platelet counts, respectively, in our patients suggest that leptin might play a role in ITP pathogenesis. Ren et al. [21] reported that an in vitro treatment with recombinant leptin or serum with a high leptin level enhanced the secretion of anti-platelet IgG from the splenocytes and peripheral blood monocytes of ITP patients. Human platelets have been reported to express leptin receptors. Leptin can increase the levels of platelet-reactive $T$ cells that subsequently cause platelet destruction [22]. Our results are in accordance with those of Zhan et al. [23], who found elevated serum leptin levels in ITP patients, a negative correlation between serum leptin levels and platelet counts, and a positive correlation between serum leptin and PAIgG levels. Additionally, our results are supported by those of Mouzaki et al. [24], who reported a 6-fold increase in the plasma leptin levels in patients with active ITP compared with those in the controls, although the leptin levels were within the control range in patients who achieved remission.

The significantly high percentage of activated platelets in our patients and the negative correlation between the activated platelets and the platelet count indicate an association between acute ITP and platelet activation. In these patients, platelet activation might act as a compensatory mechanism to reduce the bleeding that occurs due to thrombocytopenia; thus, many ITP patients do not have significant bleeding even with severe thrombocytopenia. Platelet auto-antibodies activate normal platelets in patients with ITP [25]. Shao et al. [16], Panzer et al. [26] and Hayashi et al. [27] measured the activated platelets in ITP patients and found that the percentages of CD62ppositive platelets were significantly higher in ITP patients than in other patients. The positive correlation between serum leptin and activated platelets in our patients suggests that elevated serum leptin could induce platelet activation. Elbatarny and Maurice [28] reported that leptin promotes platelet activation. In patients with thrombocytopenia of brief duration, the levels of serum leptin and activated platelets were significantly lower than those in patients with thrombocytopenia of prolonged duration. Thus, higher levels of serum leptin and activated platelets might predict a prolonged disease course.

\section{Conclusion}

The increased levels of activated platelets, serum leptin and platelet-associated antibodies in children with acute ITP suggest that these factors could play a role in disease pathogenesis. Additionally, activated platelets and serum leptin could have prognostic significance in paediatric acute ITP.

\section{Disclosure Statement}

The authors declare that they have no conflict of interest.

\section{References}

1 Rodeghiero F, Stasi R, Gernsheimer T, Michel M, Provan D, Arnold DM, Bussel JB, Cines DB, Chong BH, Cooper H, Godeau B, Lechner K, Mazzucconi MG, McMillan R, Sanz MA, Imbach P, Blanchette V, Kühne T, Ruggeri M, George JN: Standardization of terminology, definitions and outcome criteria in immune thrombocytopenic purpura of adults and children: report from an international working group. Blood 2009;113:2386-2393.

-2 Semple JW: Immune pathophysiology of autoimmune thrombocytopenic purpura. Blood Rev 2002;16:9-12.
3 Cines DB, Blanchette VS: Immune thrombocytopenic purpura. N Engl J Med 2002;346: 995-1008.

-4 Stasi R, Evangelista ML, Stipa E, Buccisano F, Venditti A, Amadori S: Idiopathic thrombocytopenic purpura: current concepts in pathophysiology and management. Thromb Haemost 2008;99:4-13.

5 Cooper N, Bussel J: The pathogenesis of immune thrombocytopenic purpura. Br J Haematol 2006;133:364-374.

-6 McFarland J: Pathophysiology of platelet destruction in immune (idiopathic) throm- bocytopenic purpura. Blood Rev 2002;16: $1-2$.

7 Cioffi JA, Shafer AW, Zupancic TJ, SmithGbur J, Mikhail A, Platika D, Snodgrass HR: Novel B219/OB receptor isoforms: possible role of leptin in hematopoiesis and reproduction. Nat Med 1996;2:585-589.

8 Matarese G, Di Giacomo A, Sanna V, Lord GM, Howard JK, Di Tuoro A, Bloom SR, Lechler RI, Zappacosta S, Fontana S: Requirement for leptin in the induction and progression of autoimmune encephalomyelitis. J Immunol 2001;166:5909-5916. 
-9 Jy W, Horstman LL, Park H, Mao WW, Valant P, Ahn YS: Platelet aggregates as markers of platelet activation: characterization of flow cytometric method suitable for clinical applications. Am J Hematol 1998;57:33-42.

-10 Panzer S, Höcker L, Vormittag R, Rieger M, Koren D, Dunkler D, Pabinger I: Flow cytometric evaluation of platelet activation in chronic autoimmune thrombocytopenia. Pediatr Blood Cancer 2006;47:694-696.

$>11$ Severinsen MT, Engebjerg MC, Farkas DK, Jensen A, Norgaard M, Zhao S, Sørensen HT: Risk of venous thromboembolism in patients with primary chronic immune thrombocytopenia: a Danish population-based cohort study. Br J Haematol 2011;152:360-362.

$>12$ Cuker A, Cines DB: Immune thrombocytopenia. Hematology Am Soc Hematol Educ Program 2010;2010:377-384.

$\checkmark 13$ Provan D, Stasi R, Newland AC, Blanchette VS, Bolton-Maggs $\mathrm{P}$, Busse JB, Chong $\mathrm{BH}$, Cines DB, Gernsheimer TB, Godeau B, Grainger J, Greer I, Hunt BJ, Imbach PA, Lyons G, McMillan R, Rodeghiero F, Sanz MA, Tarantino M, Watson S, Young J, Kuter DJ: International consensus report on the investigation and management of primary immune thrombocytopenia. Blood 2010;115: 168-186.

14 Edslev PW, Rosthøj S, Treutiger I, Rajantie J, Zeller B, Jonsson OG, NOPHO ITP Working Group: A clinical score predicting a brief and uneventful course of newly diagnosed idiopathic thrombocytopenic purpura in children. Br J Haematol 2007;138:513-516.

15 Yildirmak Y, Yanikaya-Dimirel G, Palanduz A, Kayaalp N: Antiplatelets antibodies and their correlation with clinical findings in childhood immune thrombocytopenic purpura. Acta Haematol 2006;116:75-76.
16 Shao JF, Zhan QG, Liu ZM, Zhong YG, Guan YL, Fu JP, Feng WY, Lou DJ: Significance of detecting platelet associated antibody and platelet membrane glycoprotein for diagnosis of immune thrombocytopenia (in Chinese). Zhongguo Shi Yan Xue Ye Xue Za Zhi 2004; 12:224-227.

17 Romero-Guzmán LT, López-Karpovitch X, Paredes R, Barrales -Benitez O, Piedras J: Detection of platelet-associated immunoglobulins by flow cytometry for the diagnosis of immune thrombocytopenia: a prospective study and critical review. Haematologica 2000;85: 627-631.

18 Corash L, Rheinschmidt M: Detection of platelet antibodies with a fluorescence activated flow cytometric technique; in Rose NR, Friedman H, Fahey JL (eds): Manual of Clinical Laboratory Immunology, ed 3. Washing ton, American Society for Microbiology, 1986, pp 254-257.

19 Rosenfeld CS, Nichols G, Bodensteiner DC: Flow cytometric measurement of antiplatelet antibodies. Am J Clin Pathol 1987;87:518 522.

20 Kahng J, Park HH, Han K, Choi BY, Lee W: Quantitative comparisons of antibody-binding sites of platelet glycoprotein IIb/IIIa in aplastic anemia and idiopathic thrombocytopenic purpura. Ann Clin Lab Sci 2008;38:6-11.

21 Ren H, Zhao H, Wang T, Yang Y, Han Z, Liu B, Wu Z, Tao J, Zhou B, Zhang L, Yang R, Han ZC: Leptin enhances in vitro secretion of IgG antiplatelet antibodies by splenocytes and peripheral blood mononuclear cells from patient with chronic idiopathic thrombocytopenic purpura. Clin Immunol 2006;120:205-211.
22 Dellas C, Schäfer K, Rohm IK, Lankeit M, Leifheit M, Loskutoff DJ, Hasenfuss G, Konstantinides SV: Leptin signalling and leptin-mediated activation of human platelets: importance of JAK2 and the phospholipases C $\gamma^{2}$ and A2. Thromb Haemost 2007;98:10631071.

23 Zhan M, Zhao H, Yang R, Han ZC: Serum leptin level in patients with idiopathic thrombocytopenic purpura. Eur J Haematol 2004; 72:348-352.

24 Mouzaki AM, Theodoropoulou M, Vlaha V, Maniatis AK: Leptin levels in childhood idiopathic thrombocytopenic purpura (ITP) correlate with disease activity (abstract). 10th Congress of the European Hematology Association, Stockholm, 2006.

25 Yanabu M, Nomura S, Fukuroi T, Soga T, Kondo K, Sone N, Kitada C, Nagata H, Kokawa T, Yasunaga K: Synergistic action in platelet activation induced by an antiplatelet autoantibody in ITP. Br J Haematol 1991;78: 87-93.

26 Panzer S, Rieger M, Vormittag R, Eichelberger B, Dunkler D, Pabinger I: Platelet function to estimate the bleeding risk in autoimmune thrombocytopenia. Eur J Clin Invest 2007;37: 814-819.

27 Hayashi S, Oshida M, Kiyokawa T, Aochi H, Honda S, Tomiyama Y, Kurata Y: Determination of activated platelets: evaluation of methodology and application for patients with idiopathic thrombocytopenic purpura (in Japanese). Rinsho Byori 2001;49:1287-1292.

28 Elbatarny SH, Maurice DH: Leptin-mediated activation of human platelets: involvement of a leptin receptor and phosphodiesterase 3Acontaining cellular signaling complex. Am J Physiol Endocrinol Metab 2005;289:E695E702. 